Original Research

\title{
Effect of the Irrigation Fluid Temperature on Core Temperature in Transurethral Resection of Prostate Patients Under Spinal Versus General Anaesthesia
}

\author{
Rajeev Kumar, MD'; Veena Asthana, MD'*; Jagadish Prasad Sharma, MD'; Shobha Lal, Mch² \\ 'Department of Anaesthesiology, Himalayan Institute of Medical Sciences, Jollygrant Dehradun, Uttarakhand 248I60, India \\ ${ }^{2}$ Department of Urosurgery, Himalayan Institute of Medical Sciences, Jollygrant Dehradun, Uttarakhand 248 I60, India
}

\section{"Corresponding author}

Veena Asthana, MD

Department of Anaesthesiology, Himalayan Institute of Medical Sciences, Jollygrant Dehradun, Uttarakhand 248I60, India; E-mail: drvasthana@yahoo.co.in

\section{Article information}

Received: March 14 $4^{\text {th }}$ 2018; Revised: April 20

\section{Cite this article}

Kumar R, Asthana V, Sharma JP, Lal S. Effect of the irrigation fluid temperature on core temperature in Transurethral resection of prostate patients under spinal versus general anaesthesia. Res Pract Anesthesiol Open J. 20I8; 3(I): 7-12. doi: 10.17/40/RPAOJ-3-II7

\section{| ABSTRACT |}

\section{Study Design}

Prospective, randomized control trial.

Objectives

To evaluate and compare the effect of warm and unwarmed irrigation fluid and anaesthetic technique on core temperature in patients undergoing Transurethral resection of prostate.

\section{Summary of Background Data}

Material and Methods: The present study was conducted in 80 patients belonging to age group18-75 yrs of posted for TURP under general anaesthesia or spinal anaesthesia.

Group A: General Anaesthesia with irrigation fluid at room temperature.

Group B: GeneralAnaesthesia with irrigation fluid at $37^{\circ} \mathrm{C}$.

Group C: Spinal Anaesthesia with irrigation fluid at room temperature.

Group D: Spinal Anaesthesia with irrigation fluid at at $37^{\circ} \mathrm{C}$.

Results

Amongst the four Groups, all the subjects showed consistently reduced core temperature which was statistically significant $(p<0.05)$ at all time intervals. Core temperatures were lower in the group receiving unwarmed irrigation fluid compared with the prewarmed irrigation fluid group at the end of surgery. The mean decrease in core temperature at the end of surgery $4.2105{ }^{\circ} \mathrm{F}$ in Group A $1.1105^{\circ} \mathrm{F}$. in Group B, $4.2700^{\circ} \mathrm{F}$. in Group C, $1.4250^{\circ} \mathrm{F}$ in Group D. The difference in mean core temperature was not statistically significant in Groups receiving unwarmed fluid. Statistically significant difference in mean core temperature was seen in Group B and Group D.

\section{Conclusion}

Use of prewarm irrigation fluid resulted in lesser drop in core temperature as compared than that receiving unwarmed irrigation fluid. The drop was relatively least in patients under general anaesthesia.

\section{Keywords}

Transurethral prostate resection; Core temperature; Hypothermia; Prewarmed; Irrigation fluid.

\section{Abbreviations}

TURP: Transurethral prostate resection; ETT: Endotracheal tube; SBP: Systolic Blood Pressure; DBP: Diastolic Blood Pressure; MBP: Mean Blood Pressure; ECG: Electrocardiography; NIBP: Non-Invasive Blood Pressure. 


\section{INTRODUCTION}

$\mathrm{P}$ reventing unintentional hypothermia for all surgical patients has been an important challenge for anaesthesiologist. ${ }^{1}$ Despite body temperature been a vital sign, hypothermia during Transurethral prostate resection (TURP) has received relatively little importance in the urology literature. ${ }^{2}$ Irrigation fluid as a cause of hypothermia during TURP was first reported by Rabke et al. ${ }^{3}$ The consequences of unplanned hypothermia are significant and is well documented in the existing literature. ${ }^{4}$ The type of anaesthetic technique and the temperature of irrigation fluid best for TURP is still debatable. Spinal anaesthesia is a preferred for TURP ${ }^{5}$ however general anesthesia is indicated when blockade is counterindicated, fails or is refused by the patient. The type of anaesthetic used also influence the irrigation fluid absorption and also impairs the thermoregulatory mechanisms which contributes to the development of hypothermia. ${ }^{6}$ Most patients undergoing TURP are elderly which is an important independent risk factor for developing hypothermia which increases susceptibility to intraoperative as well as post-operative complications and delays patient recovery from anaesthesia ${ }^{6}$ hence increasing the financial burden on the patient. Therefore it is critical to understand the importance of maintaining normothermia in patients specially elderly undergoing surgery. Various stratigies can be used to prevent heat loss and to lower the risk of inadvertent hypothermia associated with administering anaesthesia. Warming of irrigation fluid seems appealing to achieve normothermia, ${ }^{7}$ however studies comparing the effect of pre warmed and unwarmed irrigation fluid under different anaesthetic technique to prevent unintended hypothermia have shown conflicting results. The aim of the present study was to determine the effectiveness of warm irrigation fluid in maintaining core body temperature in patients undergoing TURP under spinal versus general anaesthesia in a limited resource setup.

\section{MATERIAL AND METHODS}

After approval from Institutional Ethical Committee and written informed consent from the patients, 80 patients scheduled for elective TURP were selected. The patients were in the age group of 60-85 years, American Society of Anaesthesiologist I and II. Patients with preexisting major cardiovascular, respiratory or endocrinal diseases, preoperative anaemia, severe electrolyte abnormality, on anticoagulant therapy or existing coagulopathy were excluded. Other exclusion criteria were patients on nitrates, angiotensin-converting enzyme (ACE) inhibitors or calcium channel blockers, as these medications might interfere with normal thermal regulation mechanisms. A thorough preoperative evaluation was done for all patients. The patients were kept nil per oral for 6 hours before surgery and received tablet diazepam $10 \mathrm{mg}$ night before and on morning of surgery with a sip of water.

In the operation theater after securing intravenous access all patients were preloaded with $500 \mathrm{ml}$ of Ringer lactate. Preoperative baseline vitals such as Electrocardiography (ECG), non invasive blood pressure (NIBP) and $\mathrm{SPO}_{2}$ were noted. The temperature of operation theater was noted and kept constant at 23 ${ }^{\circ} \mathrm{C}$. The patients were then randomly allocated into any of the four groups. Randomization was done with sealed envelope technique.

Group A: General Anaesthesia with irrigation fluid at room temperature

Group B: GeneralAnaesthesia with irrigation fluid at $37^{\circ} \mathrm{C}$

Group C: Spinal anaesthesia with irrigation fluid at room temperature

Group D: Spinal anaesthesia with irrigation fluid at at $37^{\circ} \mathrm{C}$

The patients in the group A \& B were induced by Inj. fentanyl $(2 \mu \mathrm{gm} / \mathrm{kg})$ followed by injection (inj.) Thiopentone (4-7 mg/ $\mathrm{kg})$. Ventilation was checked by gentle mask ventilation and neuromuscular blockade achieved by utilising Injection. vecuronium bromide in dose of $0.1 \mathrm{mg} / \mathrm{kg}$ the patients were ventilated with $66 \% \mathrm{~N}_{2} \mathrm{O}$ in $\mathrm{O}_{2}$ and sevoflurane $\leq 1.5 \%$ for 3 minutes. A cuffed Endotracheal tube (ETT) of appropriate size was introduced into the trachea. Anaesthesia was maintained with $66 \%$ nitrous oxide in oxygen, sevoflurane and intermittent boluses of injection vecuroniun bromide $0.08 \mathrm{mg} / \mathrm{kg}$ and inj fentanyl $1-2 \mathrm{mcg} / \mathrm{kg}$. At the end of surgery neuromuscular blockade was reversed with inj neostigmine and inj glycopyrolate in usual doses.

The patients in Group C and D were administered subarachnoid block in the sitting position using $25 \mathrm{G}$ spinal needle by midline approach and $12.5 \mathrm{mg}$ of hyperbaric bupivacaine was administered. The patient was turned to supine position. Level of the block was checked by pinprick method. Patients were covered with theater linen at room temperature during the procedure and were not actively heated. Monopolar resection was performed using cautery with cutting and coagulation setting of 100 and $60 \mathrm{~W}$ respectively A well-lubricated resectoscope (Olympus winter and IbeGmbH, Kuchnstr 61, 22045 Hamburg, Germany) and the telescope was used for resection of the prostate. The perfusion pressure was $60 \mathrm{~cm}$ of water in all cases. The temperature of the distilled water as irrigating fluid in Group A and Group C was similar to room temperature while in Group B and Group D irrigation fluid was warmed by using incubator (YARCO B.O.D) Yarco sales Pvt. Ltd., New Delhi, India. Before use irrigation fluid was put into irrigation fluid reservoir (sew water bath, scientific equipment works, New Delhi, India) which was also prewarmed up to $37^{\circ} \mathrm{C}$. The temperature of the irrigation fluid was measured with a mercury thermometer put inside the reservoir.

The core body temperature was monitored by nasopharyngeal probe introduced after explaining the procedure and well lubricating the probe and nasal passage. Nasopharyngeal temperature, NIBP, Heart rate, Systolic blood pressure (SBP), diastolic blood pressure (DBP), mean blood pressure (MBP), ECG was continuously monitored at preinduction, induction at thereafter every 15 minutes throughout the procedure. The total duration of surgery, amount of irrigation fluid used and patient satisfaction were noted. Considering a statistical power $(\beta)$ of $80 \%$, and $\alpha$ error of $5 \%$ and clinically significant of temperature difference of 1 ${ }^{\circ} \mathrm{F}$, a total 16 samples was found in each group. In order to allow for potential data loss, it was planned to recruit 20 patients to each group. 


\section{Statistical Analysis}

Data were represented in the form of mean \pm standard deviation and analysis was performed utilize SPSS-version 22 (SPSS, Software, IBM Corporation, Amrok, Newyork). $p<0.05$ was considered to be statistically significant. Nasopharyngeal temperature were recorded over the study period, comparisions were performed with analysis of variance (ANOVA) with Post-hoc comparision adjusted by Tukeys test.

\section{RESULTS}

Eighty patients were initially enrolled in each group, and none of the patient was excluded from the analysis. There was no statistically significant differences in the groups concerning base line parameters such as age, height, weight, ASA grade, duration of surgery, amount of irrigation fluid used, and ambient temperature in the operating room (Table 1). (Table 2) Illustrates observed changes in core temperature during the perioperative period. Patients in all the groups who received unwarmed and warmed irrigating fluid demonstrated a significant decrease of core body temperature. In each group temperature changes were highly significant $(p<0.05)$ .The drop in nasopharyngeal temperature from baseline to the end of surgery was Group A $98.7{ }^{\circ} \mathrm{F}$ to $93.70^{\circ} \mathrm{F}$, in Group B $98.7{ }^{\circ} \mathrm{F}$ to $96.7{ }^{\circ} \mathrm{F}$, in Group C $98.7{ }^{\circ} \mathrm{F}$ to $94.0^{\circ} \mathrm{F}$ and in Group D from $98.6^{\circ}$ $\mathrm{F}$ to $96.7{ }^{\circ} \mathrm{F}$.

Considering a statistical power $(\beta)$ of $80 \%$, and $\alpha$ error of $5 \%$ and clinically significant of temperature difference of $1{ }^{\circ} \mathrm{F}$, a total 16 samples was found in each group. In order to allow for potential data loss, it was planned to recruit 20 patients to each group.
Hypothesis is to determine the effectiveness of warm irrigation fluid to $37{ }^{\circ} \mathrm{C}$ as compared to irrigation fluid at $23{ }^{\circ} \mathrm{C}$ (which is O.T temperature) in maintaining core body temperature in patients undergoing TURP under spinal versus general anaesthesia in a limited resource setup.

As a institutional protocol the temperature of operation theater is kept constant at $23{ }^{\circ} \mathrm{C}$. Irrigation fluid at room temperature verusus prewarmed fluid to $37{ }^{\circ} \mathrm{C}$ using incubator is used in TURP surgeries .

The patients were randomly allocated into any of the four groups. Randomization was done with sealed envelope technique. The anaesthetist recording the intraoperative temperature and haemodynamic parameters was unaware about the irrigation fluid temperature used in TURP (Chart 1).

\section{DISCUSSION}

We found that the magnitude of hypothermia is not affected by mode of anaesthetic technique with unwarmed irrigant fluid. Although prewarming fluid to $37^{\circ} \mathrm{C}$ did not completely abolish intraoperative hypothermia but definitely reduce its severity in elderly patients undergoing TURP. The incidence of hypothermia was least under general anaesthesia.

Our study is unique in the way that we studied the effect of prewarmed and unwarmed irrigation fluid on core body temperature under regional as well as general anaesthesia in a single setting that none of the published trials have reported previously.

Causes of intraoperative unintentional hypothermia are multifactorial. ${ }^{8}$ Several methods of patient warming have been re-

\begin{tabular}{|cccccc}
\hline \multicolumn{7}{|l}{ Table I.Demographic Profile and the Operative Details of the Patients } \\
\hline & Group A & Group B & Group C & Group D & p value \\
\hline Total number & 20 & 20 & 20 & 20 & \\
\hline Age \pm SD (years) & $64.4 \pm 9.04$ & $68.1 \pm 9.07$ & $66.4 \pm 9.02$ & $65.6 \pm 9.90$ & $p>0.05$ \\
\hline Weight \pm SD (Kg) & $60.24 \pm 4.02$ & $59.45 \pm 9.36$ & $59.02 \pm 2.06$ & $57.0 \pm 6.80$ & $p>0.05$ \\
\hline Height $\pm S D(c m)$ & $159.4 \pm 4.24$ & $160.2 \pm 7.52$ & $160.4 \pm 2.06$ & $160.0 \pm 7.20$ & $p>0.05$ \\
\hline ASA(II/III) & $18 / 2 \pm$ & $17 / 3$ & $16 / 4 \pm$ & $15 / 5$ & $p>0.05$ \\
\hline Duration of surgery (min) & $56.20 \pm 2.42$ & $53.40 \pm 7.75$ & $54.01 \pm 6.04$ & $52.75 \pm 5.45$ & $p>0.05$ \\
\hline Amount of irrigation fluid (litres) & $7.60 \pm 4.10$ & $7.70 \pm 3.10$ & $7.82 \pm 2.14$ & $7.61 \pm 3.14$ & $p>0.05$ \\
\hline Ambient Temperture & $21{ }^{\circ} \mathrm{C}$ & $21{ }^{\circ} \mathrm{C}$ & $21{ }^{\circ} \mathrm{C}$ & $21{ }^{\circ} \mathrm{C}$ & \\
\hline
\end{tabular}

\begin{tabular}{|c|c|c|c|c|c|c|c|c|c|c|}
\hline Groups & $\begin{array}{c}\text { Pre } \\
\text { induction }\end{array}$ & $\begin{array}{l}\text { Induction / } \\
\text { Injection }\end{array}$ & $\begin{array}{c}\text { Intubation /Time } \\
\text { of effect }\end{array}$ & $\begin{array}{l}\text { Start of } \\
\text { surgery }\end{array}$ & $\begin{array}{c}15 \\
\text { minutes }\end{array}$ & $\begin{array}{c}30 \\
\text { minutes }\end{array}$ & $\begin{array}{c}45 \\
\text { minutes }\end{array}$ & $\begin{array}{c}60 \\
\text { minutes }\end{array}$ & $\begin{array}{l}\text { End of } \\
\text { surgery }\end{array}$ & $p$ value \\
\hline A & $98.46 \pm 0.18$ & $98.33 \pm 0.19$ & $97.70 \pm 0.38$ & $97.8 \pm 0.1$ & $96.8 \pm 0.8$ & $96.6 \pm 0.2$ & $96.2 \pm 0.9$ & $95.8 \pm 0.1$ & $94.2 \pm 0.2$ & $p<0.05$ \\
\hline B & $98.55 \pm 0.12$ & $98 \pm 0.14$ & $98 \pm 0.15$ & $98.6 \pm 0.8$ & $97.5 \pm 0.6$ & $97.9 \pm 0.6$ & $97.1 \pm 0.9$ & $97.8 \pm 0.6$ & $97.4 \pm 0.8$ & $p<0.05$ \\
\hline C & $98.56 \pm 0.09$ & $98.53 \pm 0.10$ & $98.23 \pm 0.10$ & $97.6 \pm 0.5$ & $96.5 \pm 07$ & $96.8 \pm 0.6$ & $95.6 \pm 0.5$ & $94.7 \pm 0.2$ & $94.6 \pm 0.5$ & $p<0.05$ \\
\hline$D$ & $98.56 \pm 0.06$ & $98.55 \pm 0.06$ & $98.39 \pm 0.10$ & $98.8 \pm 0.1$ & $98 \pm 0.3$ & $97.6 \pm 0.4$ & $97.4 \pm 0.7$ & $97.2 \pm 0.8$ & $97.3 \pm 0.6$ & $p<0.05$ \\
\hline
\end{tabular}




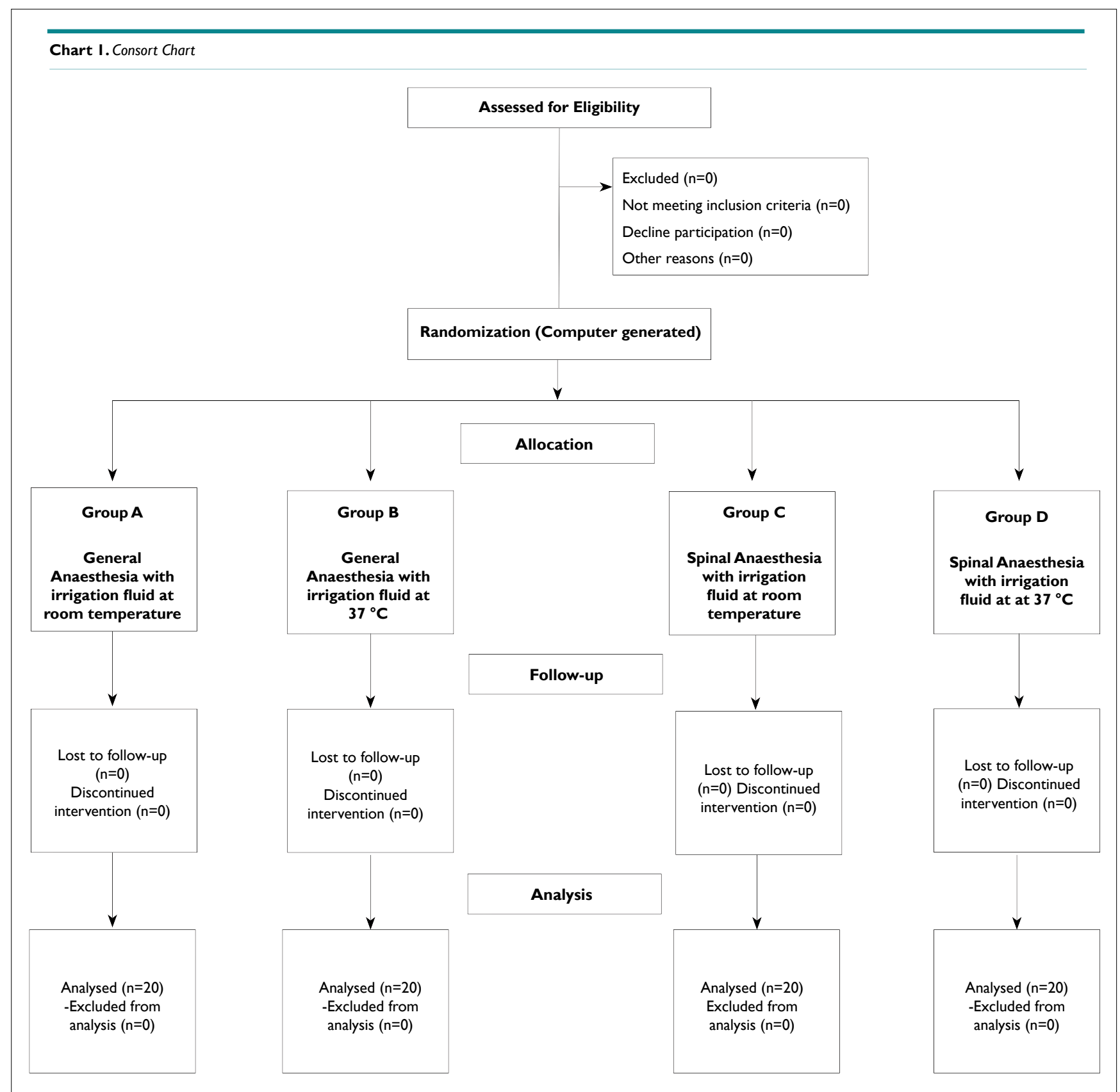

ported in clinical studies to lower the chances of inadvertent hypothermia associated with anaesthesia and surgery.

Use of irrigation fluid at room temperature as a cause of hypothermia was postulated by Winter et al. ${ }^{10}$ Similar results were observed by a study conducted in our department. ${ }^{11} \mathrm{Hahn}$ et al and Carpenter et al revealed the benefits of using warmed irrigation fluid for endoscopic procedures. ${ }^{12}$ The recently published National Institute for Health and Clinical Excellence (NICE) guidelines and Cochrane review on prevention of peri-operative hypothermia recommends that blood products and fluids administered to patients under anaesthesia should be warmed to $37.0^{\circ} \mathrm{C} \cdot \cdot^{13,14} \mathrm{Con}$ versely, other authors did not confirm this result. ${ }^{15}$ Our study and that of Dyer and Heathcote ${ }^{16}$ provide evidence that although the temperature fall was less with prewarmed irrigant it still dropped at average of $10^{\circ} \mathrm{C}$. The reason for the observation could be the heat loss as the the prewarmed fluid is flushed into the urinary bladder which can be prevented by using continuously warming irrigation system. ${ }^{17}$ On the other hand, Jaffe et al found no correlation between irrigation fluid temperatures and fall in core temperature in a TURP procedure. ${ }^{18}$

In none of our patients the core temperature fell below $93.7^{\circ} \mathrm{F}$. This may be attributed to two factors namely shorter duration of surgery (mean duration between $52.75 \pm 5.75$ to $57.50 \pm 9.67$ minutes) and lesser usage of irrigation fluid (Mean volume of irrigation fluid used $6.10 \pm 2.63 \mathrm{~L}$ to $7.61 \pm 3.14 \mathrm{~L}$ ).

Hahn et al reported that limiting surgical time to one hour may prevent hypothermia due to lesser absorption of fluid 


\section{CONFLICTS OF INTEREST}

The authors declare that they have no conflicts of interest.

\section{REFERENCES}

1. Sessler DI. Mild perioperative hypothermia. N Engl J Med. 1997; 336: 1730-1737. doi: 10.1056/NEJM199706123362407

2. Vaughan MS, Vaughan RW, Cork RC. Postoperative hypothermia in adults: Relationship of age, anesthesia, and shivering to rewarming. Anesth Analg. 1981; 60: 746-751.

3. Rabke HB, jenicek JA, khouri E. Hypothermia associated with transurethral resection of the prostate. J Urol. 1962; 87: 447-449. doi: 10.1016/S0022-5347(17)64979-6

4. Evans JW, Singer M, Chapple CR, Macartney N, Walke JM, Milroy EJ. Haemodynamic evidence for cardiac stress during transurethral prostatectomy. Br Med J. 1992; 304: 666-671. doi: 10.1136/ bmj.304.6828.666

5. Hatch PD. Surgical and anaesthetic considerations in transurethral resection of the prostate. Anaesth Intensive Care. 1987; 15: 203211. who received warm irrigation fluid under general anaest was $(1.11 \pm 0.28)$ which was significantly less $(p=0.000)$ as compared to other groups.

We measured core temperature by nasopharyngeal route which is recommended as a reliable method additionally, measurement of the skin temperatures on limbs and trunk in addition to core temperature, could have helped us in estimating mean body temperature and total heat body content. ${ }^{24}$ Another limitation of our study was that when the irrigation fluid is warmed from 17 ${ }^{\circ} \mathrm{C}$ to $37^{\circ} \mathrm{C}$ there is corresponding change in the density and dynamic fluidity of the irrigating fluid..$^{25}$ This aspect of fluid dynamic change should also be considered when it is warmed. In our study we did not look into this aspect.

\section{CONCLUSION}

We have demonstrated that intra-operative unintentional hypothermia is more common in usual practice than recorded. Both spinal as well as general anaesthesia leads to peri-operative hypothermia the incidence of which is least when prewarmed irrigation fluid is used in patients under general anaesthesia. However, this cost effective method of prewarming of irrigation fluid should be incorporated routinely in patients undergoing TURP under general or spinal anaesthesia offering decrease post operative thermal discomfort.

\section{ACKNOWLEDGEMENT}

This study was conducted after the approval of Himalayan Institute of Medical Sciences, Ethical committee.
6. Okeke LI. Effect of warm intravenous and irrigating fluids on body temperature during transurethral resection of the prostate gland. BMC Urol. 2007; 7: 15. doi: 10.1186/1471-2490-7-15

7. Dobson PM, Caldicott LD, Gerrish SP, Cole JR, Channer KS. Changes in haemodynamic variables during transurethral resection of the prostate: Comparison of general and spinal anaesthesia. $\mathrm{Br}$ J Anaesth. 1994; 72(3): 267-271.

8. Board TN, Srinivasan MS. The effect of irrigation fluid temperature on core body temperature in arthroscopic shoulder surgery. Arch Orthop Trauma Surg. 2008; 128: 531-533. doi: 10.1007/s00402007-0368-x

9. Kim YS, Lee JY, Yang SC, Song JH, Koh HS, Park WK. Comparative study of the influence of room temperature and warmed fluid irrigation on body temperature in arthroscopic shoulder surgery. Arthroscopy. 2009; 25(1): 24-29. doi: 10.1016/j.arthro.2008.08.005

10. Winter M. Effects of irrigation fluid warming on hypothermia during urologic surgery. Urol Nurs. 1994; 14(1): 6-8.

11. Singh R, Asthana V, Sharma JP, Lal S. Effect of irrigation fluid temperature on core temperature and haemodynamic changes in transurethral resection of prostate under spinal anesthesia. Anesth Essays Res. 2014; 8: 209-215. doi: 10.4103/0259-1162.134508

12. Carpenter AA. Hypothermia during transurethral resection of prostate. Urology 1984; 23: 122-124. doi: 10.1016/00904295(84)90003-7 
13. NICE (National Institute for Health and Clinical Excellence). Clinical Practice Guideline. The Management of Inadvertent Perioperative Hypothermia in Adults. UK: National Collaborating Centre for Nursing and Supportive Care; 2008: 1-567.

14. Campbell G, Alderson P, Smith AF, Warttig S. Warming of intravenous and irrigation fluids for preventing inadvertent perioperative hypothermia. Cochrane Database of Systematic Reviews 2015; 4. Art. No.: CD009891. doi: 10.1002/14651858.CD009891. pub2

15. Taufan Tenggara, Djoko Rahardjo Effect of irrigating fluid temperature on core body temperature during transurethral resection of the prostate. Med J Indones. 2005; 14: 152-156. doi: 10.1016/ S0090-4295(01)00993-1

16. Dyer PM. Heathcote PS. Reduction of heat loss during transurethral resection of the prostate. Anaesth Intensive Care. 1986; 14: 12-16.

17. Moore SS, Green CR, Wang FL, Pandit SK, Hurd WW. The role of irrigation in the development of hypothermia during laparoscopic surgery. Am J Obstet Gynecol. 1997; 176: 598-602. doi: 10.1016/S0002-9378(97)70554-4

18. Jaffe JS, McCullough TC, Harkaway RC, Ginsberg PC. Effects of irrigation fluid temperature on core body temperature during transurethral resection of the prostate. Urology. 2001; 57: 10781081. doi: 10.1016/S0090-4295(01)00993-1

19. Hahn RG. Fluid absorption in endoscopic surgery. $B r J A n$ - aesth. 2006; 96: 8-20. doi: 10.1093/bja/aei279

20. Gehring H, Nahm W, Baerwald J, et al. Irrigation fluid absorption during transurethral resection of prostate: Spinal vs General anaesthesia. Acta Anaesthesiol Scand. 1999; 43: 458-463. doi: 10.1034/j.1399-6576.1999.430415.x

21. Frank SM, Shir Y, Raja SN, Fleisher LA, Beattie C. Core hypothermia and skin-surface temperature gradients: Epidural vs. general anesthesia and the effects of age. Anesthesiology. 1994; 80: 502-508.

22. Jenkins J, Fox J, Sharwood-Smith G. Changes in body heat during transvesical prostatectomy: A comparison of general and epidural anesthesia. Anaesthesia. 1983; 38: 748-753. doi: 10.1111/ j.1365-2044.1983.tb12197.x

23. Leslie K, Sessler DI. Reduction in the shivering threshold is proportional to spinal block height. Anesthesiology. 1996; 84: $1327-$ 1331.

24. Frank SM, Shir Y, Raja SN, Fleisher LA, Beattie C. Core hypothermia and skin-surface temperature gradients. Epidural versus general anesthesia and the effects of age. Anesthesiology. 1994 Mar;80(3):502-8.

25. de Freitas Fonseca M, Andrade CM, Jr., de Mello MJ, Crispi CP. Effect of temperature on fluidity of irrigation fluids. $\mathrm{BrJ} \mathrm{An}$ aesth. 2011; 106: 51-56. doi: 10.1093/bja/aeq303 